\title{
Assessing physicians' intention to prescribe antimicrobials for chronic HIV/AIDS associated diarrhea among adults in Nigeria, using the theory of planned behavior
}

\author{
Yusuf Abdu Misau, ${ }^{1,2}$ Muhammad Bashir Faruk, ${ }^{3}$ Sabiu Abdu Gwalabe, ${ }^{4}$ \\ Usman Usman Sunusi, ${ }^{5}$ Dominic Mogere, ${ }^{2}$ Suleiman Abdallah Mbaruk ${ }^{2}$ \\ ${ }^{1}$ Department of Community Medicine, Abubakar Tafawa Balewa University Bauchi, Nigeria; \\ ${ }^{2}$ Department of Epidemiology and Biostatistics, School of Public Health, Mount Kenya University, Thika \\ Kenya; ${ }^{3}$ Department of Pediatrics, Abubakar Tafawa Balewa University Teaching Hospital Bauchi, Nigeria; \\ ${ }^{4}$ Department of Medicine, Abubakar Tafawa Balewa University Teaching Hospital Bauchi, Nigeria; \\ ${ }^{5}$ Department of Public Health, Federal Medical Center, Birnin Kudu, Jigawa, Nigeria
}

\begin{abstract}
Chronic diarrhea remains one of the commonest manifestation of HIV and a leading cause of morbidity and mortality despites gains in greater access to antiretroviral drugs and treatments of opportunistic infections globally. Yet, there is lack of precise evidence about the place of antimicrobials in chronic HIV associated diarrhea among adults. Physicians have continued to prescribe antimicrobials empirically or otherwise for chronic HIV associated diarrhea among adults.

The aim of this study is to assess Physicians' intension to prescribe antimicrobials in chronic HIV associated diarrhea among adults in Nigeria using the constructs of theory of planned behavior: Attitudes, Subjective Norms and Perceived behavioral control.
\end{abstract}

Correspondence: Yusuf Abdu Misau, Department of Community Medicine, Abubakar Tafawa Balewa University Bauchi, Nigeria.

E-mail: yusufmisau@gmail.com

Key words: Antimicrobials; chronic HIV/AIDS; diarrhea; theory of planned behavior.

Acknowledgements: the Authors are indebted to Dr Sulaiman Lawan of ATBUTH Bauchi Nigeria, who facilitates the organization of FGD to develop the study tool, Dr Usman Gwarzo of Aminu Kano Teaching Hospital Kano, Nigeria, Dr Sani Awwalu of ABU Teaching Hospital Zaria Nigeria for their supports in data collection, Mrs Titilope Badru of FHI360 Country office Abuja Nigeria who made valuable suggestions regarding statistical analysis and the entire staff of Epidemiology and Biostatistics Department, School of Public Health, Mount Kenya University, Thika Kenya.

Received for publication: 19 April 2018.

Revision received: 7 June 2018

Accepted for publication: 29 June 2018.

This work is licensed under a Creative Commons Attribution NonCommercial 4.0 License (CC BY-NC 4.0).

(C) Copyright Y.A. Misau et al., 2018

Licensee PAGEPress, Italy

Annals of African Medical Research 2018; 1:5

doi:10.4081/aamr.2018.5
An exploratory cross sectional survey was carried out. A structured questionnaire was developed following a pilot study to elicit salient beliefs among Physicians and a review of the literature. The study was carried out in 3 Northern Nigerian states among Physicians in Primary/Secondary and Tertiary hospitals in 2014. Data was analyzed using SPSS and STATA. After descriptive statistics, multiple logistic regression analysis was used to determine the relationship between the key constructs of TPB and Physician's intension to prescribe antimicrobials in chronic HIV associated diarrhea among adults.

We found strong intention to prescribe antimicrobials among Physicians respondents. The constructs of the theory of planned behavior explained $40 \%$ of variance of the Physicians' intention to prescribe antimicrobials for chronic AIDS associated diarrhea in adults. Perceived control behavior and knowledge were the most important components of the model associated with intention.

This study has further added new knowledge to the pool of evidence that Perceived Control Beliefs and Knowledge significantly influence Physicians' intention to prescribe antimicrobials in chronic AIDS associated diarrhea. This finding reinforces the utility of theory of planned behavior as a tool to study health care service provision and utilization. There is need for future studies to test if changes in perceived control behavior and knowledge will leads to changes in intention to prescribe antimicrobials for chronic AIDS associated diarrhea and ultimately leading to a change in the clinical practice of managing chronic AIDS associated diarrhea in adults.

\section{Introduction}

Chronic HIV/AIDS associated diarrhea (AAD) remains one of the major causes of morbidity and mortality despite more than three decades of using highly active antiretroviral drugs (ARVs). ${ }^{1}$ With nearly 33 million people living with HIV/AIDS worldwide, ${ }^{2}$ more than $50 \%-60 \%$ of these patients experience chronic diarrhea at one stage in the course of their aliments. ${ }^{3}$ Though diarrhea is a common complication in patients with human immunodeficiency virus infection but it is often inadequately treated. Diarrhea thus has a significant impact on quality of life (QOL) and can contribute to malnutrition, weight loss, immunosuppression, and mortality among HIV infected patients. ${ }^{4}$ In addition, diarrhea may have a significant impact on compliance with antiretroviral therapy. The perceived roles of antimicrobials in treatment of chronic AAD among adults is yet controversial. In developing countries were the 
burden of HIV/AIDS opportunistic infections are high, there are limited capabilities for isolating common organisms implicated in the etiology of chronic AAD. ${ }^{5}$ Treatments in such cases are often empirical. Yet there has been no previous study that explores Physician's decision making while prescribing antimicrobials in chronic AAD among adults.

The theory of planned behavior by Azjen and Fishbein now assumes unprecedented recognition as a tool for understanding human behaviors in a given context. ${ }^{6}$ However, salient beliefs as the first thoughts that come to a person's mind when that person is asked open-ended questions related to performing some behavior ${ }^{7}$ are rarely studied in relation to Physicians decision while prescribing antimicrobials in chronic AAD. Hence, the proponents of the famous theory of planned behavior have recommended conducting elicitation study as a pre-requisite to using the theory to determine intensions towards a given behavior. ${ }^{8}$ In this study, the three constructs of the TPB will be used to explain Physician's salient behavioral beliefs about the positive or negative consequences of antimicrobials use among patients with HIV/AIDS associated chronic diarrhea in adults: attitude toward the behavior. Salient normative beliefs about the views of other professional colleagues as well as perceived social pressure from their patients to prescribe such antimicrobials; to determine subjective norm. And salient control beliefs that Physicians may perceive to facilitate or impede prescription of antimicrobials in such patients, determine perceived behavioral control.

Chronic diarrhea in HIV/AIDS according to the World Health Organization (WHO) is passage of two or more episodes of loose watery stool in HIV patients for a duration of one month. ${ }^{9}$ However, there are different views on the exact definition of diarrhea in HIV. Some literature relates diarrhea with volume of stool rather than frequency of stool. Others defines chronic diarrhea as three or more loose per day for more than one month. ${ }^{10}$ The Centers for Diseases Control of United States of America (USA) defines chronic diarrhea in HIV as two or more loose stool of greater than four weeks duration.

Severe immunosuppression with low CD4 cells count of 300 cells $/ \mu \mathrm{L}$ has been associated with occurrence of chronic diarrhea in HIV (HIV induced diarrhea or enteropathy). ${ }^{11}$ With even extreme low CD4 cells of less than 50 cells $/ \mu \mathrm{L}$ diarrhea becomes more severe. Co-existing sexually transmitted diseases leading to proctatitis or anorectal ulcers, use of antiretroviral drugs, fat malabsorptions and gastrointestinal malignancies all predisposed to chronic diarrhea in HIV. ${ }^{12}$

Chronic AAD occurred more in developing countries and among people with low socio-economic status. ${ }^{13}$ Poor personal hygiene and malnutrition, low standard housing low literacy level are all reported to predispose to chronic AAD.

Diarrhea of infectious origin is by far more reported than noninfectious diarrhea in previous literature. However recent literature are reporting declining incidence of chronic infectious diarrhea in HIV. ${ }^{14}$ Perhaps the increasing availability of HAART might have help in better immune status among HIV patients. Several organisms are implicated as causative agents in chronic infectious HIV associated diarrhea usually reflecting the severity of background immunosuppression. Common organisms are the coccidian parasites, Cryptosporidia microsporidia, Cyclosporidia and Isospora belli organisms. ${ }^{15}$ But Giardia lamblia, Entamoeba histolytica, Mycobacterium avium complex, Clostridium difficile, Shigellosis, Campylobacter jejuni, Strongyloides stercoralis, Cytomegalovirus are well documented causative organisms. ${ }^{10}$ Non-infectious chronic HIV diarrhea is mostly associated with use of antiretroviral drugs. Particularly, nelfinavir, ritonavir, lopinavir, zidovudine, didanosine. ${ }^{16}$ Proponents of HIV enteropathy suggest HIV associated diarrhea results from colonization of the gut associated lymphoid tissues by HIV virus itself. ${ }^{17}$ This according to the theory explains why diarrhea is among the early GIT symptoms to manifest in HIV. GALT is a pivotal site for primary HIV replication and subsequent CD4 cells decline. This argument is further supported by presence of HIV RNA and DNA in biopsies of intestinal mucosa from HIV infected patients during histological examinations. ${ }^{18}$

\section{Theoretical rationale}

According to the theory proposed by Icek Azjen and Fishbein, a human behavior is guided by three kinds of considerations ${ }^{19}$ (Figure $1^{7,20}$ ):

- Beliefs about the likely consequences of the behavior (behavioral beliefs),

- Beliefs about the normative expectations of others (normative beliefs), and

- Beliefs about the presence of factors that may facilitate or impede performance of the behavior (control beliefs).

In their respective aggregates, i.e. synergistically, behavioral beliefs produce a favorable or unfavorable attitude toward the behavior; normative beliefs result in perceived social pressure or subjective norm; and control beliefs give rise to perceived behavioral control. ${ }^{21}$ In combination, attitude toward the behavior, subjective norm, and perception of behavioral control lead to the formation of a behavioral intention. As a general rule, the more favorable the attitude and subjective norm, and the greater the perceived control, the stronger should be the person's intention to perform the behavior in question. Finally, given a sufficient degree of actual control over the behavior, people are expected to carry out their intentions when the opportunity arises. Intention is therefore assumed to be the immediate antecedent of behavior. However, because many behaviors pose difficulties of execution that may limit volitional control, it is useful to consider perceived behavioral control in addition to intention. To the extent that perceived behavioral control is veridical, it can serve as a proxy for actual control and contribute to the prediction of the behavior in question.

Following our systematic review and meta-analysis, the TPB is employed to study Physician's behavioral beliefs, perceived normative beliefs and perceived control in their decision to prescribe antimicrobials for patients with chronic HIV/AIDS associated diarrhea.

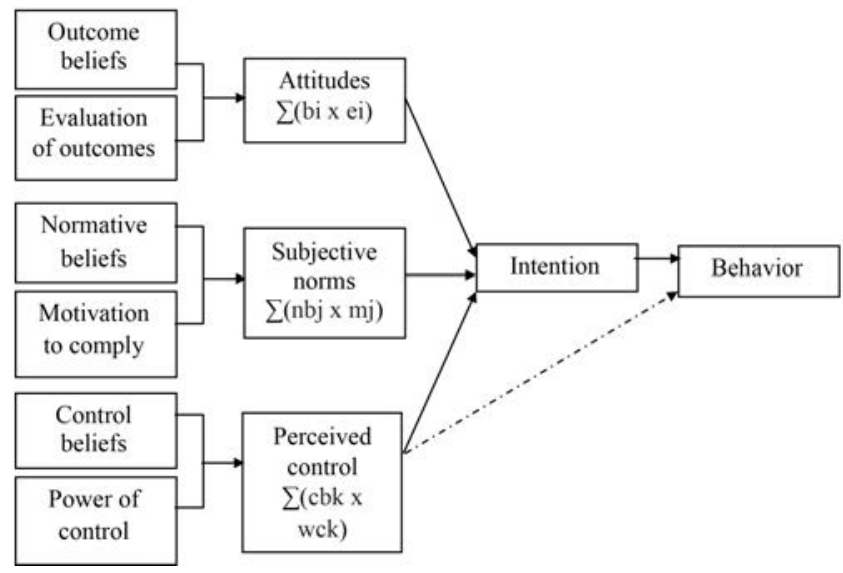

Figure 1. Theoretical framework of the theory of planned behavior. ${ }^{7,20}$ 
TPB has become popular tool in not only the studies aimed at designing strategies to help people to adopt healthy behaviors but also to help clinicians increase their uptake of treatment guidelines. ${ }^{22}$

The aims of this study is therefore to determine factors influencing Physician's intention to prescribe antimicrobials in chronic HIV associated diarrhea among adults in Nigeria using the three constructs of theory of planned behavior: Attitudes, Subjective Norms and Perceived behavioral control.

\section{Materials and Methods}

\section{Study design}

A cross sectional survey was carried out between June 2014 and September 2014. Prior to that, an elicitation study was conducted at Abubakar Tafawa Balewa University Teaching Hospital in Bauchi Nigeria in May 2014. The elicitation study was mainly to determine salient beliefs among Physicians regarding use of antimicrobials in chronic HIV associated diarrhea among adults. Elicitation study is one of the key requirements of study involving the use of theory of planned behavior. Findings from the elicitation study were used in addition to the manual for the conduct of studies using TPB to develop a 47 items structured questionnaire.

\section{Study setting}

The study was conducted in 3 Nigerian states: Bauchi, Kaduna and Kano states all in the Northern part of the country. Northern Nigeria is a sparsely densely populated region. With a prevalence of $3.6 \%$ Nigeria ranks $3^{\text {rd }}$ in the global burden of HIV/AIDS and the highest in Sub-Saharan Africa. The current official population of Nigeria is 140 million. ${ }^{23}$ The 3 states represents $14.4 \%$ of the total population of Nigeria. Kaduna State has a population of 6,066,562 Kano has 9,383,682 and Bauchi 4,676,465. All the 3 States have tertiary hospitals operated by federal government, Secondary and Primary care centers operated by the states. There are about 2500 Doctors practicing in all the 3 states put together. The largest Tertiary hospital in Northern Nigeria is located in Kaduna state. Kano state is the commercial hub of northern Nigeria. There are numerous ethnic groups in all the 3 states with Hausa language as the lingua fraca. The official language of communication in Nigeria is English. HIV care services are provided in all tertiary, secondary and selected private and primary care centers in Nigeria (Figure 2).

\section{Participants and sample size}

Relying on studies that suggest a minimum sample size of 80 (with an assumption of moderate effect size, $\mathrm{R}=0.3$ ) $^{24}$ for TPB based studies, a sample of 400 Doctors, Specialists, Residents and Medical Officers caring for HIV/AIDS Patients were considered enrolled in the study. The participants were selected by purposive and heterogeneous sampling with maximum variation to get those who will agree to participate and capture a range of responses. Consent was asked from any participant before enrollment. An information sheet with a cover letter requesting consent was attached to the front page of each questionnaire given to a participant.

\section{Study questions}

The study aims to answer the questions:

- What is the relationship between Physician's demographics and their intention to prescribe antimicrobials in chronic AIDS associated diarrhea among adults in Nigeria?
- What is the relationship between Physician's attitude, subjective norms, perceived behavioral control, knowledge and their intention to prescribe antimicrobials in chronic AIDS associated diarrhea among adults in Nigeria?

\section{Development of study tool}

There were 47 items on the structured questionnaire. The questionnaire items were designed to reflect the principal constructs of the theory of planned behavior: measures for attitude (A), perceived behavioral control (PBC), and subjective norms (SN) (societal norms and social influences). Although items were derived from the previous empirical studies, actual measurement scales to capture the context of the study were developed using the manual of TPB developed by Center for health services research, University of Newcastle United Kindom. ${ }^{25}$ The scales were then modified to the questionnaire items to match his study. Questions assessing participant's knowledge of use of antimicrobials in HIV/AIDS associated diarrhea were added to the items assessing the constructs of the TPB.
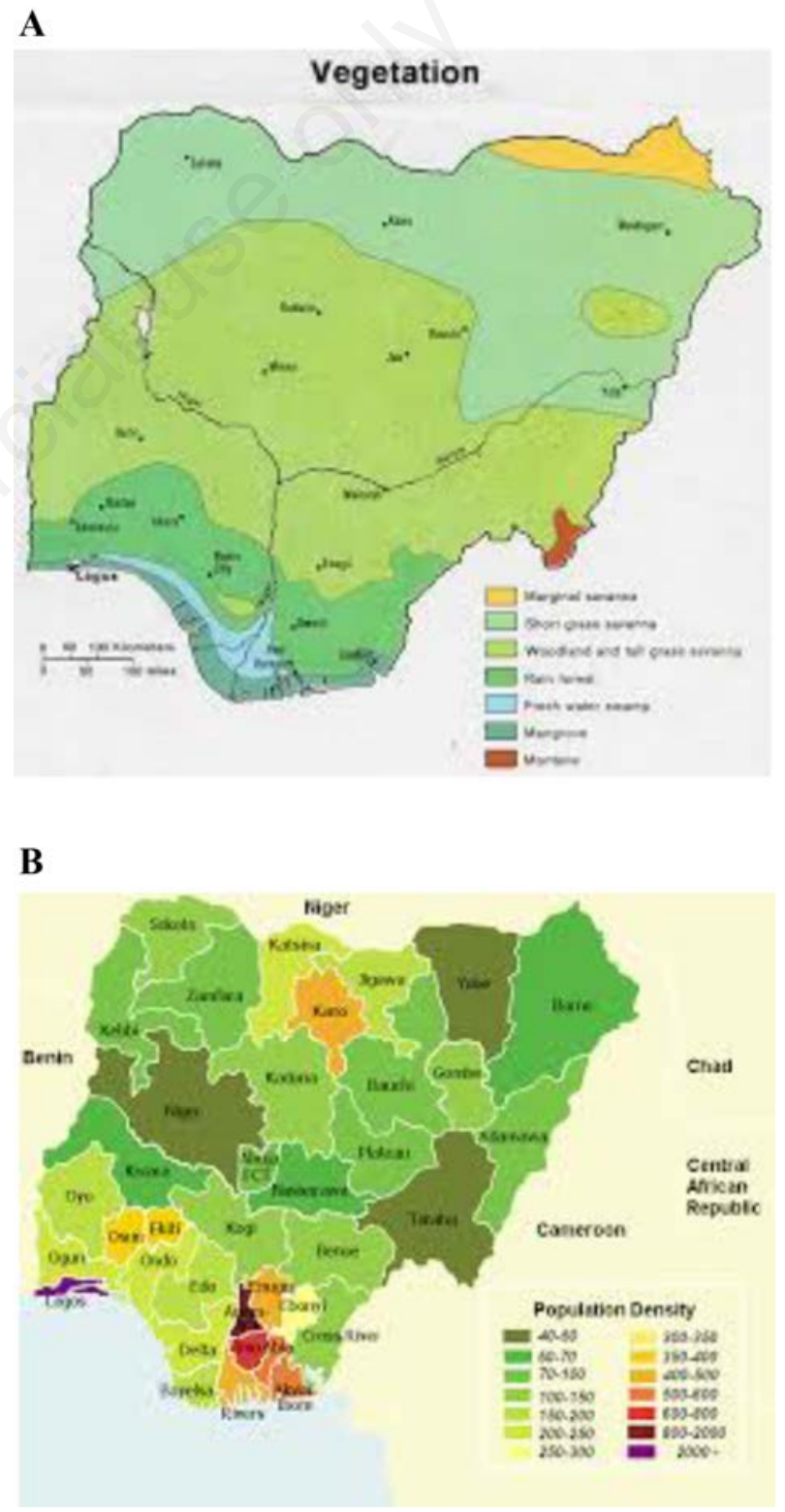

Figure 2. Map of Nigeria showing: A) vegetation; and B) population density. 


\section{Components of the questionnaire}

The first part of the questionnaire asked respondents about their socio-demographic backgrounds. Six (6) set of items were used. These include:

i) Gender; ii) Type of institution; iii) Department of practice; iv) Rank; v) Years of service in current carder; vi) Age.

The second part of the questionnaire assessed Physician's intention to prescribe antimicrobials. There were three (3) items: i) "...Proportion of patients you will prescribe antimicrobials for chronic AIDS associated diarrhea in next three months"; ii) "...will you prescribe antimicrobials empirically?..."; iii) "How difficult will it be to prescribe antimicrobials..."

The third part of the questionnaire assessed the three constructs of the theory of planned behavior non-sequentially. Attitude towards antimicrobials prescription was assessed by asking questions about outcome beliefs and evaluation of the outcome. There were 10 items, which include: i) "...antimicrobials will reduce risk of minor complications...”; ii) “...antimicrobials will reduce risk of major complications..."; iii) "...antimicrobials will reduce time taken for diarrhea to resolve..."; iv) "...antimicrobials cause GE side effects like diarrhea and vomiting..."; v) "...antimicrobials will suppress normal flora and cause thrush...”; vi) “...antimicrobials will increase resistance to common drugs..."

Subjective Norms was assessed by asking questions about normative beliefs and motivation to comply. There were 10 items, which include: i) "...if I don't prescribe antimicrobials they will consult another partner.."; ii) "...antimicrobials will increase their satisfaction with my care"; iii) "...antimicrobials will reduce length of the consultation"; iv) "...antimicrobials will reduce likelihood to reattend clinic with same complain "; v) "...antimicrobials will give them a placebo effect".
Perceived Control Beliefs was assessed by asking questions about control beliefs and power of control. There were 10 items, which include: i) "...My hospital thinks I should stop prescribing antimicrobials.."; ii) "...Our unit head in the hospital think I should not prescribe antimicrobials..”; iii) “...Pharmacists in this hospital do not like antimicrobials.."; iv) "...GPs in the practice think that I should not prescribe antimicrobials..”; v) "...My patients with AIDS associated chronic diarrhea think that I should prescribe antimicrobials"; vi) "...I am familiar with the WHO guideline on management of chronic diarrhea...”; vii) “...If a patient with chronic AIDS associated diarrhea specifically asks for an antimicrobials, then I will prescribe one whether it is medically indicated or not". viii) "...It is not possible to satisfy these patients without prescribing antimicrobials"; ix) "...I am more inclined to prescribe antimicrobials for patients of a lower social class"; $x$ ) "...It is important to give these patients something to end the consultation"; xi) "...When treating these patients with antimicrobials, I will also prescribe an antifungal agent"; xii) “...I don't know the cause... I will prescribe an antimicrobials so that I don't miss something"; xiii) "...I will feel uncomfortable if I do not prescribe antimicrobials for these patients"; xiv) “...I will feel uncomfortable if I do prescribe antimicrobials for these patients"; xv) "...To explain to these patients that antimicrobials are not required is very difficult".

Knowledge about use of antimicrobials in chronic AIDS associated diarrhea was asked using 8 items, which include: i) “...If I am to prescribe antimicrobial in these patients I am more likely to use: Antibiotics, Antiparasites, Antiviral, Antifungal, Combination regime"; ii) "..My antimicrobials choice in these patients is informed by Evidence Based Practice"; iii) "..My antimicrobials choice in these patients is informed by my clinical experience of its effectiveness"; iv) "..I will prescribe antimicrobials to these patients because most of them respond well to emphirical treatment"; v) “..I will prescribe antimicrobials to these patients

Table 1. Basic demographic profiles of respondents: gender, qualification, years in practice, type of hospital of practice and age.

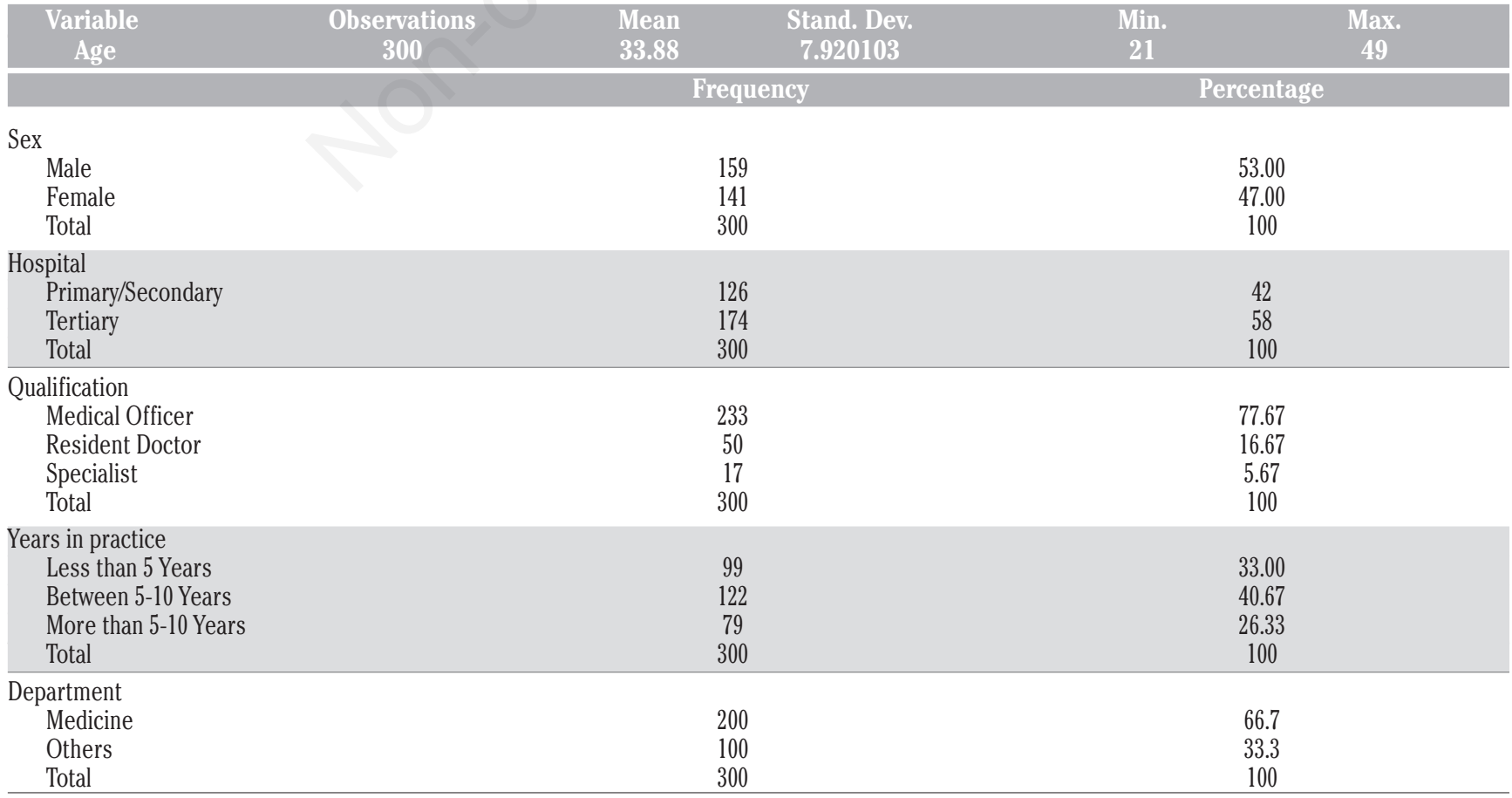


because the organisms causing the diarrhea are sensitive to common antimicrobials"; vi) "...I will not prescribe antimicrobials to these patients because the diarrhea is mostly not due to infectious causes".

\section{Piloting of questionnaire}

A draft of the questionnaire was piloted among 5 selected respondents. Items in the questionnaire include sets of demographic questions to provide information about the sample, followed by mix of questions measuring the three key predictor variables of the TPB model. Azjen suggested mix-up of questions measuring the predictor variables of the TPB and sequential arrangements. ${ }^{25}$

Respondents were asked to comment about difficulties in answering the questionnaire, length of the items, tautology, ambiguity and depth of the thoughts in construction of the questionnaire items. Responses from the pilot study were used to effect necessary corrections in the wordings of the questionnaire.

\section{Data collection}

Respondents were contacted directly by trained research assistant who issue questionnaires to respondents and retrieve on the spot. Respondents were tracked at clinics, CME centers, wards and offices within their places of assignment.

\section{Statistical analysis}

Data cleaning and analysis were performed using SPSS v16 and STATA v13 software. Responses to 5-point scales were coded on unipolar 1-5 scales. The data was assessed for skewness before analysis. Descriptive statistics was used to summarize all demographic data about respondents. Test for correlation coefficient was used to test relationship between key constructs of TPB and intention to prescribe antimicrobials for chronic HIV associated diarrhea. A multiple logistic regression analysis was used to develop a model explaining relationship between the variables

\section{Results}

\section{Basic demographic characteristics}

A total of 400 participants were contacted, 350 responded among the 400 participants contacted. However, 50 respondents did not fill their questionnaire appropriately or accepted to participate but failed to return their questionnaire. The remaining 300 responses (75\%) were analyzed. Among them, 159 (53\%) were males while 141 (47\%) were females. Majority of the respondents were Medical Officers 233 (77.7\%) followed by Resident Doctors $50(16.7 \%)$ while there were only $17(5.7 \%)$ specialist Doctors. Most respondents were practicing at tertiary centers 192 (54.9\%) while $158(45.1 \%)$ of the respondents were practicing at either secondary or primary centers. In terms of unit of work, most respondents were in a general medicine 200 (63.7), while those in GOPD and other remaining departments were 100 (33.3\%). Respondents practicing between 5-10 years since graduation were more 122 $(40.7 \%)$ than those who were less than 5 years in practice 99 (33\%). Those practicing for more than 10 years since graduation were $79(26.3 \%)$. The mean age of all respondents was 33.88 (SD 7.92). The minimum age among respondents was 21 years while the maximum age was 49 years (Table 1).

General Description of Intention to prescribe antimicrobials for chronic AIDS associated diarrhea among respondents are reported in Tables 2-5.

In Table 2 the majority of the respondents intends to prescribe antimicrobials to their patients with chronic AIDS associated diarrhea $(\mathrm{N}=161,53.1 \%)$. Some of the respondents were not sure whether to prescribe or not $(\mathrm{N}=44,14.1 \%)$ while somewhere not willing to prescribe at all ( $\mathrm{N}=52,17.3 \%)$

However, in Table 3 the majority were not willing to prescribe antimicrobials for chronic AIDS associated diarrhea without sensitivity results $(\mathrm{N}=76,25.3 \%)$, Though a good number $(\mathrm{N}=64$, $21.3 \%$ ) were willing to prescribe without even sensitivity test. Those unsure of their intention were 57 (19\%). While $49(16.3 \%)$ were willing to prescribe for less than half of all the patients they will see.

In Table 4 a larger number of the respondents $(\mathrm{N}=87,29 \%)$ reported they will find it very difficult to prescribe antimicrobials without sensitivity results. Although 71 respondents (23.7\%) reported opposite view (Not difficult). Only a small number $(\mathrm{N}=38,12.7 \%)$ were not sure of their difficulty with antimicrobials

Table 2. (Q1) In the next three months, what proportion of patients you will see in the clinic will you prescribe antimicrobials for AIDS associated chronic diarrhea?

\begin{tabular}{lcc} 
Antimicrobial prescription & Frequency & Percentage \\
in next 3 months & & \\
$100 \%$ & 161 & 53.1 \\
$50 \%$ & 32 & 10.1 \\
\hline Not sure & 44 & 14.1 \\
Less than $50 \%$ & 11 & 3.1 \\
\hline None at all & 52 & 17.3 \\
Total & 300 & 100 \\
\hline
\end{tabular}

Table 3. (Q2) In the next three months, what proportion of patients you will see in the clinic will you prescribe antimicrobials for AIDS associated chronic diarrhea without sensitivity result?

\begin{tabular}{lcc} 
Antimicrobial prescription & Frequency & Percentage \\
in next 3 months & & \\
$100 \%$ & 64 & 21.3 \\
$50 \%$ & 54 & 18.0 \\
\hline Not sure & 57 & 19.0 \\
Less than 50\% & 49 & 16.3 \\
\hline None at all & 76 & 25.3 \\
Total & 100 & 100 \\
\hline
\end{tabular}

Table 4. (Q3) How difficult will it be for you to prescribe antimicrobials for these patients empirically in the next 3 months?

\begin{tabular}{lcc}
$\begin{array}{l}\text { Difficulty in antimicrobial } \\
\text { prescription in the next } 3 \\
\text { months }\end{array}$ & Frequency & Percentage \\
Not difficult & 71 & \\
Difficult & 70 & 23.7 \\
Not sure & 38 & 23.3 \\
Somehow very difficult & 34 & 12.7 \\
Very difficult & 87 & 11.3 \\
Total & 300 & 29.0 \\
\hline
\end{tabular}


prescription in chronic AIDS associated diarrhea.

When all the three questions assessing intention were analyzed, Sex was found to be significantly associated with overall intention to prescribe antimicrobials and intention to prescribe antimicrobials without sensitivity results. However no statistically significant association between sex and intention to prescribe antimicrobials empirically (P-values, 0.000, 0.037 and 0.238 respectively). Respondent's department of practice was strongly associated with all the three components of intention to prescribe antimicrobials (P-values 0.000, 0.001 and 0.000). Respondent's level of qualification was only significantly associated with intention to prescribe antimicrobials empirically.

None of the questions assessing intention was found to be significantly associated with type of hospital where respondents are practicing (P-values $0.405,0.815,0.337)$, and with the respondent's years in practice (P-values $0.391,0.6900 .949$ ).

Prior to carrying out logistic regression analysis, Pearson's coefficient of correlation test (Table 6) was done to test for association between the key constructs in the theory: Attitude of Physicians, Their Subjective Norms, Perceived Control Beliefs and their Knowledge towards antimicrobials in chronic AIDS asso- ciated diarrhea with Intention to prescribe the drugs. The test shows statistically significant association with 3 among the 4 components (Attitude, Control Beliefs, and Knowledge, $\mathrm{r}=0.3,0.5,0.5$ respectively, $\mathrm{P}<0.05)$. Physician's Subjective Norms was not significantly associated with Intention $(\mathrm{r}=0.03 \mathrm{P}>0.05)$.

In a sequential logistic regression analysis, beta regression of Intention to prescribe antimicrobials with demographic profiles of Physicians was assessed (Table 7) above. Physician's Department of Practice and their Years in Practice were found to be statistically significant variables, $(\mathrm{P}=0.000$ and 0.001 respectively). Gender, Rank, Type of Institution, and Age were not statistically significant contributors to the initial model.

The second model examines the relationship between intention regarding antimicrobials prescription controlling for selected significant variables, i.e. Department of Practice and Years in Service. The model provides a high $40.4 \%$ explanation of the variance of intention to prescribe antimicrobials $(\mathrm{F}=40.4 \%, \mathrm{P}<0.05)$. Perceived Control Behaviors and Knowledge of antimicrobial prescription were significantly related to the Intention, whereas Attitudes and Subjective Norms were not (Table 8).

Table 5. Association of intention to prescribe antimicrobials for chronic AIDS associated diarrhea with basic demographic profiles of respondents.

\begin{tabular}{|c|c|c|c|c|c|c|c|c|c|c|}
\hline \multirow{2}{*}{ Variable } & \multirow{2}{*}{$\begin{array}{l}\text { Sex } \\
\chi^{2}\end{array}$} & \multicolumn{3}{|c|}{ Rank } & \multicolumn{2}{|c|}{ Department } & \multicolumn{2}{|c|}{ Years in practice } & \multicolumn{2}{|c|}{ Hospital type } \\
\hline & & P-value & $\chi^{2}$ & P-value & $\chi^{2}$ & P-value & $\chi^{2}$ & P-value & $x^{2}$ & P-value \\
\hline$I^{*}$ & 20.4 & 0.000 & 11.0 & 0.199 & 75.1 & 0.000 & 8.5 & 0.391 & 4.0 & 0.405 \\
\hline II** & 10.2 & 0.037 & 6.9 & 0.543 & 17.8 & 0.001 & 6.5 & 0.690 & 1.5 & 0.815 \\
\hline III*** & 5.1 & 0.238 & 24.2 & 0.002 & 56.8 & 0.000 & 2.6 & 0.949 & 4.5 & 0.337 \\
\hline
\end{tabular}

*In the next three months, what proportion of patients you will see in the clinic will you prescribe antimicrobials for AIDS associated chronic diarrhea? **In the next three months, what proportion of patients you will see in the clinic will you prescribe antimicrobials for AIDS associated chronic diarrhea without sensitivity result? ***How difficult will it be for you to prescribe antimicrobials for these patients empirically in the next 3 months?

Table 6. Pearson's coefficient of correlation between intention and attitude, subjective norms control beliefs and knowledge towards prescribing antimicrobials for chronic AIDS associated diarrhea.

\begin{tabular}{|c|c|c|c|c|c|}
\hline Variable & Intention & Attitude & Subjective norms & Control belief & Knowledge \\
\hline Intention & 1.00 & & & & \\
\hline Attitude & $\begin{array}{l}0.29 \\
0.01\end{array}$ & 1.00 & & & \\
\hline \multirow[t]{2}{*}{ Subjective norms } & 0.043 & 0.06 & 1.00 & & \\
\hline & 0.57 & 0.26 & & & \\
\hline Control belief & $\begin{array}{l}0.53 \\
0.01\end{array}$ & $\begin{array}{l}0.40 \\
0.02\end{array}$ & $\begin{array}{l}0.12 \\
0.01\end{array}$ & 1.00 & \\
\hline \multirow[t]{2}{*}{ Knowledge } & 0.45 & 0.39 & 0.16 & 0.60 & 1.00 \\
\hline & 0.02 & 0.01 & 0.01 & 0.01 & \\
\hline
\end{tabular}

Table 7. Beta multiple logistic regression model of basic demographic profiles with intention to prescribe antimicrobials for chronic AIDS associated diarrhea.

\begin{tabular}{|c|c|c|c|c|c|}
\hline Intention & Coef. & Std. Err. & $\mathrm{t}$ & $P>t$ & Beta \\
\hline Gender & 0.02 & 0.33 & 0.07 & 0.94 & 0.00 \\
\hline Rank (qualification) & -0.18 & 0.31 & -0.58 & 0.56 & -0.03 \\
\hline Age (years) & -0.03 & 0.02 & -1.39 & 0.16 & -0.08 \\
\hline Department & 2.85 & 0.37 & 7.74 & 0.00 & 0.43 \\
\hline Institution of practice & -0.225 & 0.33 & -0.67 & 0.50 & -0.04 \\
\hline Years in practice & 0.50 & 0.21 & 2.36 & 0.02 & 0.12 \\
\hline
\end{tabular}


Table 8. Beta multiple logistic regression model of intention to prescribe antimicrobials with attitude, subjective norms, perceived control beliefs and knowledge adjusted for Department of practice and years in practice.

\begin{tabular}{lccccc}
\hline Intention & Coef. & Std. Frr. & $\mathrm{t}$ & P>t & Beta \\
Department of practice & 1.66 & 0.32 & 5.15 & 0.01 & 0.25 \\
Years in practice & 0.45 & 0.18 & 2.60 & 0.01 & 0.18 \\
\hline Attitude & 0.04 & 0.03 & 1.26 & 0.21 & 0.06 \\
Subjective norms & -0.05 & 0.03 & -1.64 & 0.10 & -0.08 \\
\hline Control beliefs & 0.15 & 0.03 & 5.19 & 0.00 & 0.30 \\
Knowledge & 0.11 & 0.03 & 3.71 & 0.00 & 0.22 \\
\hline
\end{tabular}

\section{Discussion}

Judicious use of antimicrobials is highly emphasized by experts and policy makers especially when dealing with immunecompromised patients. ${ }^{8}$ Beliefs that early institution of antimicrobials leads to shorter course of diarrhea and perceived delays in culture and sensitivity leads to high rates of empirical treatment of perceived infectious diarrhea, even when literature have established that $50 \%$ of infectious diarrhea are self-limiting within 3 days. ${ }^{26}$ Unwarranted use of antimicrobials predisposes to high level of resistance at individual and community level. Chronic AIDS associated diarrhea is seen more commonly in low socioeconomic settings and with higher likely to have infective etiologies. ${ }^{27}$ This study aims to find if any, association between Physicians' basic demographic profile with their intention to prescribe antimicrobials and the components of the theory of planned behavior. We therefore sort to know if Attitude, Subjective Norms and Perceived Social Pressure as well as Knowledge of antimicrobials have any association with Physicians' intention to prescribe antimicrobials as has been established in previous studies of human behavior using the same theory for other conditions. Majority of our respondents (53\%) have intention to prescribe antimicrobials to $100 \%$ of their patients with chronic AIDS associated diarrhea during encounter in the clinic. In addition, put together, $75 \%$ of the respondents were disproportionately willing to prescribe antimicrobials even without sensitivity result. Our first study (a systematic review and meta-analysis) found that antimicrobials can be of benefit where infectious etiologies by way of detection of parasites prior and after prescription of antimicrobials are established.

However this study has established that perceived social pressure by patients and co-workers as well as work place policies with knowledge of antimicrobials accounted for $40.4 \%$ of variance in the Physicians' intention to prescribe antimicrobials for chronic AIDS associated diarrhea in adults. Our finding agrees with previous literature that assesses Physicians' intention regarding utilization of various therapeutic options using the Theory of Planned Behavior. Our study did not find attitude and subjective norms as significant factors determining Physicians' intention to prescribe antimicrobials. Previous literatures have reported variations in assessing associations of key constructs of TPB with intention to perform a given behavior. ${ }^{28}$

Some of the limitations of this study include the fact that although the TPB has been successfully used by many researchers to predict health behaviors and intentions as well as health service provision and utilizations, the theory nonetheless has some limitations inherent within it. i) It assumes individuals have the pre-requisite to carry a given behavior. ii) It failed to account for certain variables such as fear or threat which may play a significant role in carrying out a given behavior. iii) Its a linear decision model which does not consider possibilities of changes over time. iv) It addressed PCB but it is silent about actual behavioral control. v) The time frame between Intent and Behavioral action is not explicitly addressed by the theory.

\section{Conclusions}

Our first study has provided for the first time empirical evidence that antimicrobials as a whole have beneficial effects in settings of established infectious AIDS associated diarrhea among adults. However this study has further added new knowledge to the pool of evidence that Perceived Control Beliefs and Knowledge significantly influence Physicians' intention to prescribe antimicrobials in chronic AIDS associated diarrhea. This finding reinforces the utility of theory of planned behavior as a tool to study health care service provision and utilization. There is need for future studies to test if changes in perceived control behavior and knowledge will leads to changes in intention to prescribe antimicrobials for chronic AIDS associated diarrhea and ultimately leading to a change in the clinical practice of managing chronic AIDS associated diarrhea in adults.

\section{References}

1. Kelly P. HIV-related diarrhoea. Aids Action 1998;39:7.

2. UNAIDS. UNAIDS Report on the global AIDS epidemic 2012. New York: 2012. p. 110.

3. Winson SKG. Management of HIV-associated diarrhea and wasting. J Assoc Nurses AIDS Care 2001;12:55-62.

4. Poles MA, Fuerst M, McGowan I, et al. (). HIV-related diarrhea is multifactorial and fat malabsorption is commonly present, independent of HAART. Am J Gastroenterol 2001;96: 1831-7.

5. Alemu A, Shiferaw Y, Getnet G, et al. Opportunistic and other intestinal parasites among HIV/AIDS patients attending Gambi higher clinic in Bahir Dar city, North West Ethiopia. Asian Pacific J Trop Med 2011;4:661-5.

6. Ajzen I. The theory of planned behavior. Organ Behav Hum Decis Process 1991;50:179-211.

7. Ajzen I. From intentions to actions: a theory of planned behavior. In: J. Kuhl and J. Beckmann (Eds.), Action control from cognition to behavior. Vol. 2. Springer: 1985. pp. 11-39.

8. Walker AE, Grimshaw JM, Armstrong EM. Salient beliefs and intentions to prescribe antibiotics for patients with a sore 
throat. Br J Health Psychol 2001;6:347-60.

9. Morris SS, Cousens SN, Lanata CF, Kirkwood BR. Diarrhoeadefining the episode. Int J Epidemiol 1994;23:617-23.

10. Wilcox CM. Etiology and evaluation of diarrhea in AIDS: a global perspective at the millennium. World J Gastroenterol 2000;6:177-86

11. Kulkarni SV, Kairon R, Sane SS, et al. Opportunistic parasitic infections in HIV/AIDS patients presenting with diarrhoea by the level of immunesuppression. Indian J Med Res 2009; 130:63-6.

12. Konate A, Minta D, Diarra M, et al. Intestinal parasitosis during AIDS diarrhoea. Bull Soc Pathol Exot 1990;98:33-5.

13. Monés J, Gurguí M, Cadafalch J. Diarrhea in patients with AIDS. Curr Treat Opt Gastroenterol 2006;9:280-6.

14. Monforte A, Sabin C, Phillips A, et al. The changing incidence of AIDS events in patients receiving highly active antiretroviral therapy. Archiv Intern Med 2005;165:416-23.

15. Carcamo C. Etiologies and manifestations of persistent diarrhoea in adults with HIV-1 infection: a case-control study in Lima, Peru. J Infect Dis 2005;191:11-9.

16. Divanon F, Leroyer R, Cloitre F, Le Doze F. HIV protease inhibitors adverse reactions. J Pharm Clin 1998;17:61-70.

17. Bartlett JG, Belitsos PC. AIDS enteropathy. Clin Infect Dis 1992;15.

18. Simon D. Evaluation of diarrhea in HIV-infected patients. Gastroint Endos Clin N Am 1998;8:857-67.
19. Fishbein M, Ajzen I. Belief, attitude, intention and behaviour: an instruction to theory and research. Addison-Wesley: 1975.

20. Armitage CJ, Conner M. Efficacy of the theory of planned behaviour: a meta-analytic review. Br J Soc Psychol 2001;40:471-99.

21. Fishbein M, Ajzen I. Predicting and changing behavior: the reasoned action approach. New York: Psychology Press; 2010.

22. Kortteisto T, Kaila M, Komulainen J, et al. Healthcare professionals' intentions to use clinical guidelines: a survey using the theory of planned behaviour. Implement Sci 2010;5:51.

23. NPC. Nigerian population figures; 2012. Available from: http://www.population.gov.ng/ Accessed: October 26, 2014.

24. Cohen J. Statistical power analysis (2nd ed.). Hillsdale, NJ: Erlbaum; 1988.

25. Francis JJ. Constrcuting questionnaire based on the theory of planned behaviour, A manual for health service researchers. 2004 p. 42.

26. Oldfield EC, Wallace MR. The role of antibiotics in the treatment of infectious diarrhea. Gastroenterol Clin N Am 2001;30:817-35.

27. Wingfield T, Pennell A, Blanchard TJ. Current and evolving clinical options for HIV-infected patients with chronic diarrhoea. Clin Med Insights Ther 2011;487.

28. Weber A, Dwyer T, Mummery K. Morphine administration by paramedics: an application of the theory of planned behaviour. Injury 2012;43:1393-6. 